九州大学学術情報リポジトリ

Kyushu University Institutional Repository

\title{
A Philosophical Aspect of Eating Food Animals and Food Plants
}

Shimojo, Masataka

Laboratory of Regulation in Metabolism and Behavior, Division of Animal and Marine Bioresource

Sciences, Department of Bioresource Sciences, Faculty of Agriculture, Kyushu University

https://doi.org/10.5109/1800844

出版情報：九州大学大学院農学研究院紀要. 62 (1)，pp.111-113，2017-02-24. Faculty of Agriculture, Kyushu University

バージョン :

権利関係 : 


\title{
A Philosophical Aspect of Eating Food Animals and Food Plants
}

\author{
Masataka SHIMOJO* \\ Laboratory of Regulation in Metabolism and Behavior, Division of Animal and Marine Bioresource Sciences, \\ Department of Bioresource Sciences, Faculty of Agriculture, Kyushu University, \\ Fukuoka 812-8581, Japan \\ (Received November 4, 2016 and accepted November 4, 2016)
}

\begin{abstract}
This study investigated the philosophical aspects of eating agricultural products (food animals and food plants), using the viewpoint of growth mechanics and symmetry. The results obtained were as follows. (i) Introducing growth mechanics into basic growth function gave not only a positive function (individual human body weight) but also a negative function (agricultural products whose weights were expressed using the human body weight). Those two functions resulted from symmetry about the differentiation of basic growth function that showed an accelerated increase. Symmetry and accelerated increase were considered physical laws that basic growth function showed. (ii) The negative value was interpreted as the disappearance of agricultural products by being eaten by the individual human. This was regarded as the symmetry breaking between humans and agricultural products. (iii) It was suggested that the thing similar to depriving animals and plants of lives occurred at the inside of the human body, in the human society, and in the universe. Gap-widening societies and wars were examples occurring in the human society. (iv) It might be impossible for humans to escape from those physical factors (symmetry breaking, accelerated increase) causing the deprivation activity.
\end{abstract}

Key words: accelerated increase, agricultural product, human, philosophical aspect, symmetry breaking

\section{INTRODUCTION}

Humans have to eat agricultural products in order to not only maintain lives but also increase body weights in the growth period. To eat food animals and food plants is to kill them. Humans have been depriving food animals and food plants of lives throughout the human history. It is known that the humans' habit of eating animal meats influenced the humans' thoughts and activities in Europe (Sabata, 2009). Fujihara (2014) suggests the importance of food and eating in the understanding of historical science, social science and human science. In the early stage of human evolution, escaping from dangerous predators against humans was one of the important factors that influenced the humans' social activities (Yamagiwa, 2016). Hunting, fishing and agriculture have put humans at the high position of the food chain. There is, however, a thought that all forms of life are of equal value, an issue that is philosophically important. Understanding the philosophical aspects of the humans' habit of eating food animals and food plants is considered very difficult. Various viewpoints based on human science, social science and natural science are required in order to investigate this issue.

The present study was designed to investigate the philosophical aspects of eating food animals and food plants, using the viewpoint of growth mechanics and symmetry.

\section{RELATIONSHIPS BETWEEN HUMANS AND AGRICULTURAL PRODUCTS}

\section{Description of humans and agricultural products}

\section{based on growth mechanics}

The increase or maintenance of body weight of the individual human is usually expressed using growth function. Among many kinds of growth functions including flexible functions (Bertalanffy, 1957; Richards, 1959), basic growth function (Blackman, 1919; Brody, 1945) is the simplest one that shows symmetry about the differentiation of exponential function. This symmetry is based on the accelerated increase of exponential function. Symmetry and accelerated increase are considered physical laws that basic growth function shows. Thus,

$$
W=W_{0} \cdot \exp (r \cdot t),
$$

where $W=$ body weight, $r=$ relative growth rate, $t=$ time, $W_{\mathbf{0}}=$ body weight at $t_{\mathbf{0}}$.

Because there is a difficulty in applying the single value of relative growth rate $(r)$ to the growth curve of long period, the accumulation of many values of $r$ that varies with time might give an approximation to the growth curve of long period. When based on this procedure, the feature of symmetry about the differentiation of exponential function is almost kept throughout the growth curve of long period. This is because the concept of symmetry is a key point of this study that investigates the relationship between humans and agricultural products.

Shimojo et al. (2006) interpreted basic growth function using the viewpoint of growth mechanics. This was conducted by combining basic growth function (1), its first derivative and second derivative, as shown in (2) (4).

$$
\frac{d W / d t}{W}=\frac{d^{2} W / d t^{2}}{d W / d t}=r,
$$

\footnotetext{
* E-mail: mshimojo@agr.kyushu-u.ac.jp
} 


$$
\begin{aligned}
\left(\frac{d W}{d t}\right)^{2} & =W \cdot \frac{d^{2} W}{d t^{2}}, \\
& =\left(W_{0} \cdot r \cdot \exp (r \cdot t)\right)^{2} .
\end{aligned}
$$

Equation (4) gives a positive solution (5) and a negative solution (6),

$$
\begin{aligned}
& \frac{d W}{d t}=W_{0} \cdot r \cdot \exp (r \cdot t), \\
& -\frac{d W}{d t}=-W_{0} \cdot r \cdot \exp (r \cdot t) .
\end{aligned}
$$

Thus,

$$
\begin{aligned}
& W=W_{0} \cdot \exp (r \cdot t), \\
& -W=-W_{0} \cdot \exp (r \cdot t) .
\end{aligned}
$$

Introducing the viewpoint of growth mechanics into basic growth function mathematically demands not only a positive value but also a negative value. This leads us to the understanding of the relationship between humans and agricultural products.

The positive values $\left(W, W_{0}\right)$ in function (1) show the individual human body weight. The negative values $\left(-W,-W_{0}\right)$ in function (7) show the amount of agricultural products (food animals and food plants) eaten by the individual human, where the amount of agricultural products is expressed using the individual human body weight.

However, when food animals and food plants are alive, they take positive values as the individual human does. This shows symmetry between humans and agricultural products.

\section{Symmetry breaking between humans and agricul- tural products}

If the negative value in (7) is interpreted as the disappearance of food animals and food plants by being eaten by the individual human, then this is regarded as the symmetry breaking that occurs between humans and agricultural products. This is because food animals and food plants that took positive values when they were alive are forced to take negative values by being killed for the human food, in contrast to the individual human who is allowed to keep taking positive values.

Fujihara (2014) says that the food is a mass of the carcass of living things that were pounded, chopped and roasted by humans. Maintaining the lives of humans is to keep depriving animals and plants of lives. We cannot escape from this deprivation activity, once we are born. The birth and existence of the individual human depends totally on depriving animals and plants of lives.

However, if based on the life equality among humans, animals and plants, then depriving animals and plants of lives is a sin that the individual human originally has. If humans do not want to commit this sin, the only thing that they can do might be to close the history of humans.

\section{Are humans equal to agricultural products?}

Combining functions (1) and (7) gives

$$
\begin{aligned}
0 & =W-W \\
& =W_{\mathbf{0}} \cdot \exp (r \cdot t)-W_{\mathbf{0}} \cdot \exp (r \cdot t) .
\end{aligned}
$$

Function (8) suggests that the individual human $\left(W, W_{\mathbf{0}}\right)$ and agricultural products $\left(-W,-W_{0}\right)$ appear from zero. In other words, the individual human body is mathematically equal to agricultural products. This is biologically right because the individual human body is composed of agricultural products. The individual human body is just a thing that the agricultural products transformed their forms. Fujihara (2014) boldly says that because humans are composed of foods, humans might be foods too.

\section{The thing similar to depriving animals and plants of lives occurs at the inside of the human body}

Like humans who deprive animals and plants of lives, immune substances deprive pathogenic microbes of lives at the inside of the human body. The immune system that regulates pathogens at the inside of the human body resembles the police or military system that regulates criminals in the human society.

\section{The thing similar to depriving animals and plants of lives occurs in the human society}

Humans have been discriminating against food animals and food plants throughout the human history. Bringing this discrimination into the human society leads to the advent of the 'chosen people', the racial discrimination, the gap-widening society, the outbreak of wars and so on. Those have long been causing plenty of tragedies in the human history (Sabata, 2009). The reason of battles or wars in humans is more complex than that of battles in wild animals (Yamagiwa, 2016).

\section{The thing similar to depriving animals and plants of lives occurs in the universe}

Black holes eat cosmic substances to increase the size of them in the universe, and on the earth humans eat food animals and food plants to increase the body weight of them. Since black holes are under the control of physical laws, humans might be under the control of physical laws too. Investigating the cosmic events might lead to the understanding of humans' activities.

\section{Deprivation activity common to all existence}

Because the concept of deprivation is common to all existence, the deprivation activity might be under the control of physical laws at the basic level. Functions (1), (7) and (8) give two physical factors; symmetry breaking and accelerated increase.

In the human society, those two factors give the outbreak of wars and the promotion of gap-widening society. Both of them are serious problems often seen in today's world. It might be impossible for humans to escape from 
those physical factors (symmetry breaking, accelerated increase) that cause the deprivation activity.

\section{REFERENCES}

Bertalanffy, L. von. 1957 Quantitative laws in metabolism and growth. Quart. Rev. Biol., 32: 217-231

Blackman, V. H. 1919 The compound interest law and plant growth. Ann. Bot., 33: 353-360

Brody, S. 1945 Time relations of growth of individuals and populations. In "Bioenergetics and Growth - with special reference to the efficiency complex in domestic animals", Reinhold Publishing Corporation, New York, pp. 484-574
Fujihara, T. 2014 Eating and thinking. Editorial Republica Co., Ltd., Tokyo (written in Japanese)

Richards, F. J. 1959 A flexible growth function for empirical use. J. Exp. Bot., 10: 290-300

Sabata, T. 2009 The thought of meat eating. 58th print., Chuokoron-shinsha, Inc., Tokyo (written in Japanese)

Shimojo, M., K. Ikeda, Y. Asano, R. Ishiwaka, H. Sato, Y. Nakano, M. Tobisa, N. Ohba, M. Eguchi and Y. Masuda 2006 Introducing viewpoints of mechanics into basic growth analysis - (I) Three aspects of growth mechanics compared with three laws of motion -. J. Fac. Agr., Kyushu Univ., 51: 285-287

Yamagiwa, J. 2016 Where did the violence come from? 8th print., NHK Publishing, Inc., Tokyo (written in Japanese) 